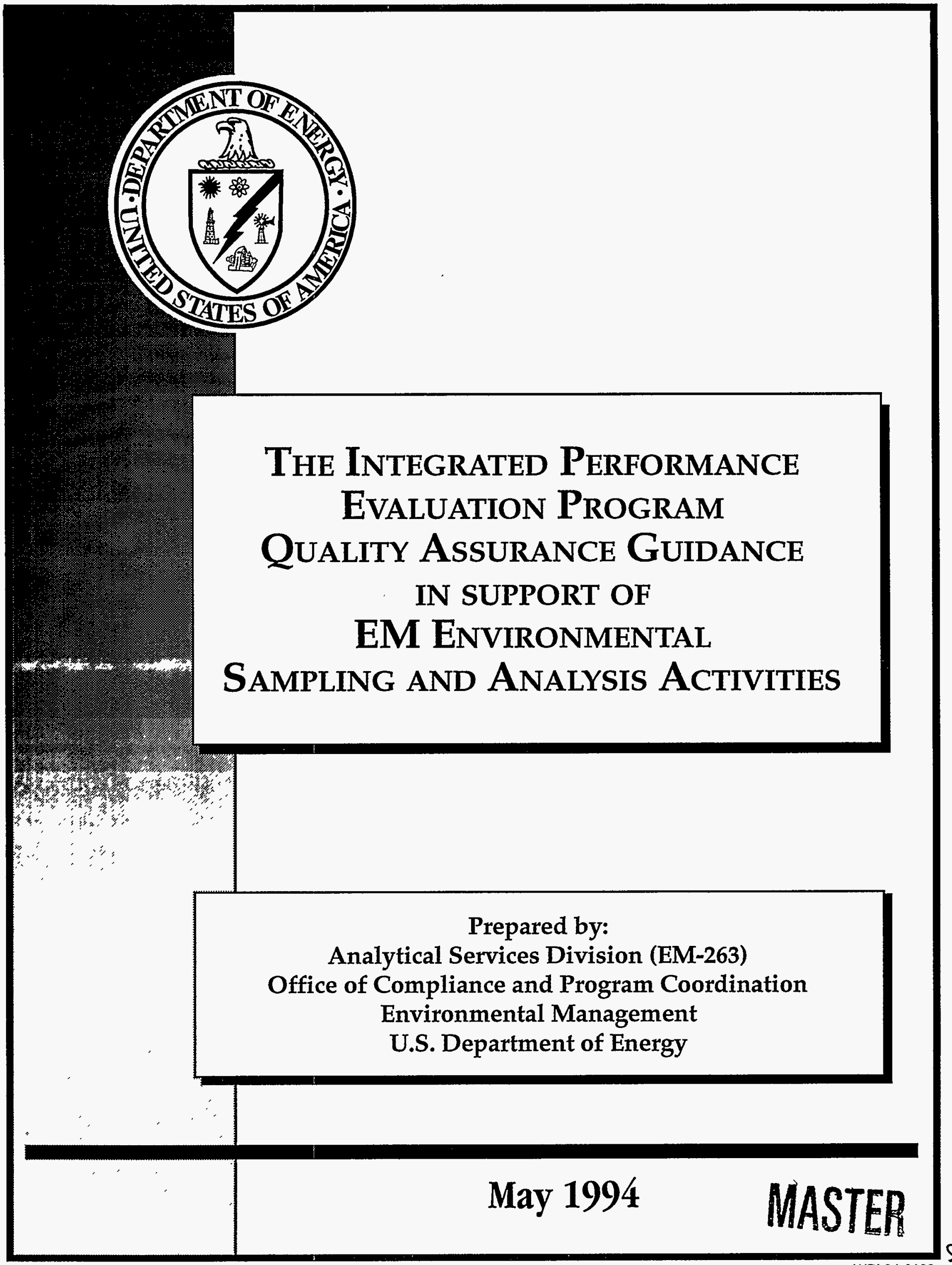




\section{TABLE OF CONTENTS}

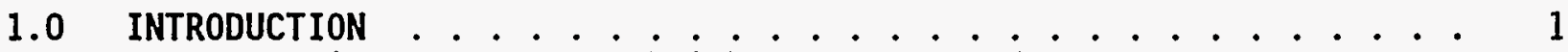

1.1 Requirements to establish an Integrated Performance

Evaluation Program (IPEP) ................. 1

1.2 Purpose . . . . . . . . . . . . . . . . . . . 1

1.3 Scope ......................... 2

1.4 IPEP Program Description ................. . . 2

1.4.1 Notification of Performance ........... . 4

1.4.2 Corrective Actions . . . . . . . . . . . . . . . . . 4

1.5 Relationship of the IPEP to Other Analytical Service Program

Elements . . . . . . . . . . . . . . . . . . . . . 5

1.5.1 Resource Management (RM) . . . . . . . . . . 5

1.5.2 Analytical Support (AS) ............. 5

1.5.3 Qual ity Assurance (QA) . . . . . . . . . . . . 6

1.6 Relationship to Regulatory Requirements and Existing

1.7 References .................... . . . 7

2.0 PE PROGRAM DESCRIPTIONS ................. 8

2.1 Laboratory Participation ............. 8

2.1.1 Regulatory Performance Evaluation Programs . . . . 8

2.1.2 DOE EML QAP Performance Evaluation Program ..... 10

2.1.3 EM Performance Evaluation Programs ........ 14

2.1.4 EM Site-Specific Performance Evaluation Program . . 16

2.2 Numerical Performance Evaluation ............ 16

2.3 References ................ 17

3.0 TECHNICAL GUIDANCE FOR THE DEVELOPMENT OF PE SAMPLE MATERIALS . . . 18

3.1 Technical Criteria . . . . . . . . . . . . . 18

3.1.1 Analytes of Interest ............ 19

3.1.2 Concentration Ranges ............. 19

3.1.3 Sample Matrix . . . . . . . . . . . . 20

3.2 Available Performance Evaluation Samples ......... 20

3.3 Production of New Materials . . . . . . . . . . . . 21

3.3.1 Identification of Need . . . . . . . . . . 21

3.3.2 Sources of Candidate Materials . . . . . . . . 21

3.4 Certification of Proficiency Samples ........... 23

3.4.1 Expert Laboratory Certification . . . . . . 23

3.4.2 Multiple Laboratory Certification ........ 23

3.4.3 Performance Based Certification ......... 24

3.5 Performance Evaluation Sample Storage . . . . . . . . . . . . 24

3.6 References ................. 24

4.0 LABORATORY CLASSIFICATION AND PERFORMANCE TESTING . . . . . . . . 26

4.1 Classification of Laboratories . . . . . . . . . . . . . 26

4.2 Submission of Blind Performance Evaluation Samples ..... 26

4.3 Performance Evaluation Sample Data Base . . . . . . . . 26

APPENDIX I - LIST OF ACRONYMS . . . . . . . . . . . . . 28 


\section{DISCLAIMER}

This report was prepared as an account of work sponsored by an agency of the United States Government. Neither the United States Government nor any agency thereof, nor any of their employees, make any warranty, express or implied, or assumes any legal liability or responsibility for the accuracy, completeness, or usefulness of any information, apparatus, product, or process disclosed, or represents that its use would not infringe privately owned rights. Reference herein to any specific commercial product, process, or service by trade name, trademark, manufacturer, or otherwise does not necessarily constitute or imply its endorsement, recommendation, or favoring by the United States Government or any agency thereof. The views and opinions of authors expressed herein do not necessarily state or reflect those of the United States Government or any agency thereof. 


\section{DISCLAIMER}

Portions of this document may be illegible in electronic image products. Images are produced from the best available original document. 


\section{PERFORMANCE EVALUATION PROGRAM GUIDANCE}

\subsection{INTRODUCTION}

Performance Evaluation (PE) materials or samples are a necessary and required element of quality assurance and quality control (QA/QC) programs covering environmental data collection. Regulatory drivers and DOE orders mandate laboratory participation in specific programs. The performance sample provides an external reference for monitoring individual laboratory and environmental programs, e.g., U.S. Environmental Protection Agency's (EPA) Office of Water or U.S. Department of Energy's Office of Environmental Restoration and Waste Management (EM). Performance evaluation programs can also be used for internal monitoring and assessment purposes (e.g., selection process for subcontractors or estimating environmental data variability). This guidance introduces key issues associated with these distinctly different applications. It also evaluates alternative approaches and provides details covering design, development, and use of PE materials appropriate for a variety of field program activities.

In addition, this document provides a description of EM's Integrated Performance Evaluation Program (IPEP). The purpose of IPEP is to integrate information from existing PE programs with expanded $Q A$ activities to develop information about the quality of radiological, mixed waste, and hazardous environmental sample analyses provided by a 71 laboratories supporting EM programs. The IPEP uses existing PE program when available and appropriate for use by EM; new PE programs will be developed only when no existing program meets EM's needs. EM-263 is developing and implementing strategies for compiling and analyzing PE results, maintaining these results in the IPEP data base, and monitoring to assure that needed corrective actions are taken.

\subsection{Requirements to establish an Integrated Performance Evaluation Program (IPEP)}

Requirements for establishing and integrating Performance Evaluation Program participation originate from several sources:

- EM's compliance with environmental and safety laws and regulations,

- EM's need to enhance the technical validity and legal admissibility of environmental data,

- direction from the Secretary of Energy in 1989 to establish an analytical quality assurance program to support EM in response to DOE/IG findings,

- DOE Order 5700.6C which establishes QA requirements for DOE, and

- Sen-6E which establiishes assessment and self-assessment requirements for DOE.

\subsection{Purpose}

This document describes DOE's internal PE programs and external, regulatory driven PE programs, e.g., Environmental Protection Agency (EPA) certification. 
In addition, the document gives guidance covering design, development, and application of PE materials that support specific site uses (e.g., evaluation of subcontractors, site-specific assessment of measurement variability, etc.)

This guidance addresses several goals:

- identifies specific PE sample programs and contacts to establish program participation;

- identifies specific requirements for participation in DOE's internal and external (i.e., regulatory) programs;

- identifies key issues relating to the application and interpretation of $P E$ materials for EM headquarters and field office managers, and

- provides technical guidance covering selection, development, and use of PE materials for site-specific activities.

\subsection{Scope}

The requirement for participation in the EM PE programs applies to all EM personnel and support service contractors (when invoked by contract or other written direction) performing EM analytical laboratory tasks. This guidance does not apply to other DOE organizations or contractors performing support service for other DOE organizations.

Specific sections of this guidance are directed to EM program managers at headquarters and field offices (e.g., participation requirements and issues for application). Detailed technical guidance applies to all DOE contractors and subcontractors that are designing data collection activities, performing environmental analyses, or reviewing EM's environmental data collection programs. Specifically, this guidance is appropriate for field sample management organizations that contract analytical services and evaluate environmental analyses.

Requirements for the IPEP participation will be introduced, implemented, and monitored through field offices and local sample management offices. IPEP will collect, organize, evaluate, and report individual EM laboratory performance results to EM headquarters and field management.

IPEP's description of required PE program participation does not mean duplication of current efforts, e.g., multiple analyses of the same water monitoring sample for IPEP and again for regulatory reporting. Participation does require sample receipt, analysis, data reporting, and direct access to results from the sponsoring organization, e.g., EPA, by IPEP management.

\subsection{IPEP Program Description}

The IPEP consists of laboratory participation in specified PE programs. Participation in the IPEP covers DOE and external programs which address all analytical parameters and matrices processed and for which performance materials are available. The regulatory based component of the IPEP includes separate, individual hazardous and radioactive sample materials from several sources. The IPEP assures DOE's adherence to external requirements, integrates 
PE program results, and monitors laboratory support of EM programs. PE programs, which will supply data to EM as part of the IPEP, will include EPA regulatory programs, the Environmental Measurements Laboratory (EML) Radiological Quality Assessment Program (QAP) and The Radiological and Environmental Sciences Laboratory (RESL) Mixed Analyte PE program (MAPEP).

The IPEP functions as an umbrella, or clearinghouse, for PE program results. The use of information from multiple PE programs allows a more global assessment of individual laboratory performance, as well as providing a means of more fairly comparing a set of laboratories for a specific analytical area. If a laboratory has performed poorly in one PE program, its participation in a similar PE program may indicate that the laboratory does have proficiency in the given analyte-matrix area. The use of information from multiple PE programs also has economic impacts, in that if a given laboratory can demonstrate proficiency in a PE program that provides the relevant matrixanalyte types of interest to DOE, the laboratory may be exempt from participating in another PE program providing similar matrix-analyte types, (assuming there are no regulations requiring that the laboratory participate in both PE programs).

EM-263 has designed the IPEP as a tool to assess analytical performance, identify areas for improvement, and demonstrate progress. The IPEP provides continuous feedback to headquarters and Field Office Management on the performance of the various analytical laboratory facilities providing data for EM projects. The requirement that all laboratories participate in regulatory compliance and technical data quality PE programs provides a platform whereby each laboratory is evaluated individually and as a member of the community of laboratories. Priority areas for individual and group quality improvements are identifiable, based in part, on the results of the IPEP.

The IPEP is also developing a scoring procedure for PE programs to address the Data Quality objectives (DQO) concept. This procedure is designed to allow use of multiple methods and to allow fair comparisons of laboratories with dissimilar participation patterns in PE programs. This procedure also identifies areas where efforts to improve even an excellent assessment score are most appropriate. For example, laboratory missing only one or two parameters will receive a very high summary score giving a superficial indication of "no problem." However, if the specific parameters missed, e.g., plutonium, mercury, or polychlorinated biphenyls, are hazardous materials or radionuclides that drive site decisions performance relative to data use is obviously not acceptable, regardless of numeric score. Traditional acceptance limits, e.g., EPA's window of $>90 \%$ for acceptability, are not absolute in relieving laboratory responsibility to identify and correct errors. The summary score is a starting point for assessing laboratory performance, but laboratory and headquarters management should evaluate all unacceptable reported results for impact on site activities.

EM's management of the IPEP consists of specification of program requirements to reduce unnecessary duplication of effort; design, development, and distribution of new PE materials; evaluation of PE sample results; corrective action follow-up; and expansion of program materials to meet program needs. Participation in the IPEP requires the laboratory to analyze PE samples, supply DOE with PE sample results, and correct deficiencies. A laboratory should have demonstrated proficiency in the analysis of a given analyte/matrix 
combination by successful analysis of that analyte/matrix combination in a PE program prior to analyzing samples for an EM program.

An essential aspect of IPEP is matching laboratory participation to its routine analytical activities. Laboratories that run only high concentration samples cannot be held to the same standards of precision that trace level laboratories are expected to meet. However, if a laboratory runs both high concentration samples, e.g., waste tank characterization and processing, and low level samples to demonstrate "non-detection" at regulatory level, the facility should particjpate in programs providing low concentration samples. A laboratory that can't demonstrate adequate quality across this range cannot reliably support site decision regarding regulatory levels of concern. The purpose of this program is to assure that DOE's analytical support is appropriate and consistent with project requirements. Some laboratories may not attain precision and accuracy required because of background or contamination or because of operating requirements, e.g., hot cel] procedures. In these cased local efforts should be made to excuse participation in current regulatory programs as inappropriate for the laboratory mission. However, laboratories that are deemed inappropriate to analyze low concentration PE samples, cannot run regulatory program analyses, e.g., NPDES, CERCLA, RCRA, to determine compliance at concentrations approaching action limits. Risks of false negatives and positive decisions for these samples are not acceptable. For the same reason, these "excused" laboratories are also not appropriate to monitor subcontract laboratories that process samples at trace levels.

\subsubsection{Notification of Performance}

The IPEP has examined the scoring procedures of the various sponsoring organizations and the existing national PE Programs. EM-263 has the responsibility to determine the assessment procedures for all EM-sponsored programs (e.g., MAPEP) and will consider supplemental techniques to assess performance on EPA sponsored programs. However, EM should accept the pass/fail decision of the sponsoring regulatory agency. Summaries of laboratory problems that require corrective action will be distributed through joint reports from $E M-20,-30$, and 40 - to the Field 0ffices. This report will require field execution of corrective actions and will be evaluated by EM-263.

In addition to reports received from the sponsoring organization, IPEP will prepare a report of the performance of EM laboratories. Each laboratory will receive their individual evaluation, a relative ranking among all laboratories taking part in the evaluation, and an explanation of the scoring system. The combined results across multiple submissions determine a laboratory's performance. The Field Sample Management Offices (FSMOs) and EM Program Offices will receive compiled summaries of the individual laboratory reports for the IPEP.

\subsubsection{Corrective Actions}

Laboratories will have sixty (60) days to submit a corrective action report to the responsible EM management in response to the deficiencies noted in the findings of the evaluation group of the sponsoring organization (i.e., DOE or EPA). Corrective actions will be reviewed for adequacy. Those labs failing to meet the criteria or qualifications should conduct an internal systems review and initiate corrective action. They should submit a report of findings and 
actions to the responsible EM management and apply for reconsideration. Upon review of the report of findings and corrective actions, the responsible EM management may:

- find the laboratory qual ified,

- elect to audit the laboratory and assess their qualifications, or

- re-test the Taboratory through submission of additional PE samples.

The specific course of action should be coordinated with the FSMO to assure the availability of qualified laboratories to meet EM's needs for analytical services. EM-263, in conjunction with other EM Headquarters Groups, will use PE program results, the problems identified, and the associated corrective actions as a primary component of assessment programs.

\subsection{Relationship of the IPEP to Other Analytical Service Program Elements}

EM-263 has been tasked by EM to develop and implement a Quality Assurance Program for EM Environmental Sampling and Analysis (ESA) activities. The Analytical Service Program elements are interdependent in that the design and implementation of each element depends on the involvement of participants from the other programs. The IPEP provides data to and receives feedback from the other programs. It provides a common data base in which the contributions of the various programs can be evaluated. The Analytical Services Program is divided into three core areas: Resource Management, Analytical Support, and Quality Assurance.

\subsubsection{Resource Management (RM)}

The RM group is responsible for long term planning and assuring the availability of analytical laboratory services to the DOE complex. This is accomplished through its National Sample Management Program (NSMP), Field Sample Management Programs (FSMPs), Needs and Capacity Assessment Program, and Data Management Program. The FSMPs are responsible for distribution of samples and information at the local 1eve1. The FSMPS provide information to the IPEP either directly or through the NSMP as to the quantity and quality of the analytical Taboratory services. In addition, the IPEP depends heavily on the FSMP to design and conduct site-specific studies to determine the quality of the analytical data. In turn, the IPEP and NSMP provides the RM group with a timely assessment of the contractors capable of conducting the various analytical laboratory services. This information, coupled with estimates of capacity permits the RM group to assure access to acceptable laboratories and aid planning to meet future resource needs.

\subsubsection{Analytical Support (AS)}

The AS group is responsible for technical aspects of physical, chemical, radiochemical, hydrogeological, geophysical, biological, microbiological, and remote sensing analytical support for EM programs. This includes developing a methods compendium of reliable sampling and analytical methods and modifying existing methods or developing new methods as required. The IPEP interacts with the AS group in identifying appropriate PE samples for method 
characterization studies. These studies support the development and selection of appropriate quality methods. Through evaluations provided by the IPEP, the AS methods compendium group can quickly and cost-effectively evaluate the efficacy of the analytical methods being used by the 7 aboratory community and prioritize needs for methods development.

\subsubsection{Quality Assurance (QA)}

The QA group is responsible for field sampling, field analytical, and analytical Taboratory QA for EM programs. The data variability/uncertainty inherent in field and analytical laboratory activities should be known. This is supported through implementation of EM-263's Quality Assurance Program which includes these guidance documents, the Integrated Performance Evaluation Program (IPEP), the Assessment Program, and the Data Quality Objectives

Program. The data from laboratory participation in the IPEP, coupled with performance information provided by other programs and the laboratory, is the yardstick by which laboratory quality is assessed. The IPEP analytical results are an on-going indicator of possible problem areas within the laboratories and meet requirements for an independent reference of laboratory performance and a proactive internal QA Program. The. IPEP will also provide reports in support of the audit program, both for routine scheduled audits and to identify the need of oversight in the case of poor laboratory performance by an individual laboratory. These reports will include recent historical data as well as current performance, so that a single poor performance report can be put in perspective.

\subsection{Relationship to Regulatory Requirements and Existing Programs}

The DOE, the Nuclear Regulatory Commission (NRC), the U.S. Environmental Protection Agency (EPA), and the Department of Defense (DOD) have initiated a joint effort to harmonize or standardize requirements for $Q A$ efforts. Existing DOE and regulatory programs have been used as models for the EM IPEP program. Special efforts have been made to involve Federal, state, and local regulatory representatives in information and technology transfer efforts so they understand and recognize the validity of clata developed under the auspices of the IPEP for use in their decision making process. Representatives of these groups work with the group of technical experts responsible for the design and implementation of the EM IPEP.

The objective of the requirements and concepts provided in this supplement is compatibility with and technical enhancement of existing regulatory $Q A$ requirements. However, this guidance may not address a 11 specifications and requirements detailed in various local, state, and Federal programs. To ensure that all specifications and regulatory requirements are met, the analytical laboratory organization should consult their specific regulatory program requirements, quality assurance program requirements, project plans, and any other applicable site documents.

An important aspect of laboratory procurement is to include requirements for participation in regulatory driven and DOE PE programs. Participation is defined by site-specific needs. However, free access to all reported analytical results directly from the program sponsor (e.g., U.S. EPA) should be granted to both the contracting organization and to EM-263. This access is necessary to assure timely and accurate monitoring of EM's national program. 
Both national and program results are distributed to the Field offices and to Headquarters funding organizations.

This document is not meant to create a separate QA program organization or activity. QA activities and the participation described in this document should already be incorporated into various existing laboratory processes and documents and need not be located in one document. If these programs don't exist, they should be incorporated into existing internal assessment programs.

While this document does not cover DQO or QA Program development, employees and management should be trained sufficiently to give them a thorough knowledge of applicable project QA PIans and DQO requirements and concepts. The concepts of Total Quality Management (TQM) and continuous improvement should be applied throughout the planning, implementation, oversight, and assessment phases of projects. Training should emphasize that the over application of requirements not required to satisfy project requirements, resulting in excessive project costs, is nearly as important as inadequate attention to requirements.

A primary function of the IPEP is to support internal laboratory assessment of their performance, i.e., self-assessment. Performance results are presented to prioritize specific laboratory problem areas so that corrective actions can be focused most productively. This is consistent with the Total Quality Management emphasis essential to improve EM data collection.

\subsection{References}

1. U.S. Department of Energy. September 23, 1986. Order 5700.6C, Quality Assurance, Assistant Secretary for Environment, Safety and Health, Rev. 3, Washington, DC: Government Printing Office/Document Control.

2. U.S. Department of Energy. June 29, 1990. Order 5400.1, General Environmental Protection Program, Assistant Secretary for Environment, Safety and Hea7th, Chg 1, Washington, DC: Government Printing office/Document Control.

3. U.S. Department of Energy. December 21, 1990, Office of the Inspector General Report No. 0293; and August 12, 1991, Office of the Inspector Genera] Report No. 0295, Washington, DC: Government Printing Office/Document Control.

4. U.S. Department of Energy. 1991. Quality Assurance Requirements and Description, Office of Environmental Restoration and Waste Management.

5. U.S. Department of Energy. January 29, 1992. Analytical Services Program Five-Year Plan, Office of Environmental Restoration and Waste Management, Laboratory Management Division. 
2.0 PE PROGRAM DESCRIPTIONS

An effective QA oversight program should have an independent evaluation as the bas is for monitoring the effectiveness of its internal qualitiy control and :QAil activities. EM has made the determination that thi siandependent eval uation 10 requirement : sha 1 ibe met bysparticipation in esitablished regulatory and DOE, PE

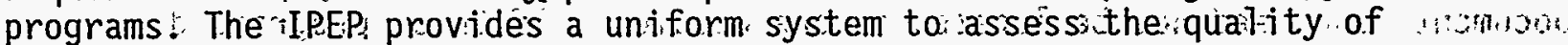
ana $7 y$ tical 1:aboratony data, to improve thei performance of $E M$ and isubconitractior laboratories, and to help determine the qualifications of analytical

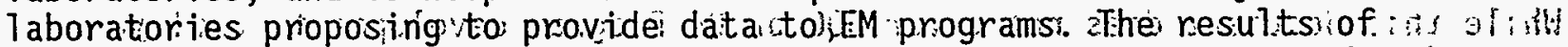
performance on othe interl aboratory lstudies provide sar stang ib́lenrecord andian uns

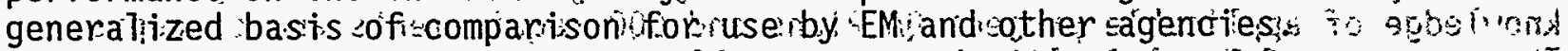

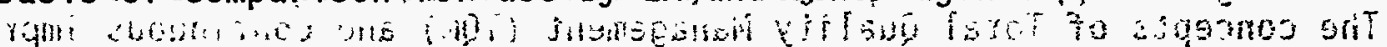

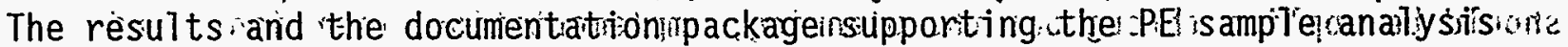

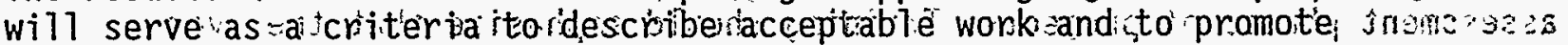
improvement Those Thaboratories meeting sthecperformancen eriteria ifor tihe :PE aqu

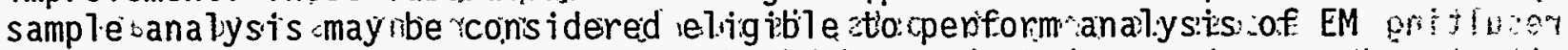
environmental samples. Evaluations should be conducted rasinecessarys itour jus.is: maintain confidence in the Taboratory and to meet QA Program/project

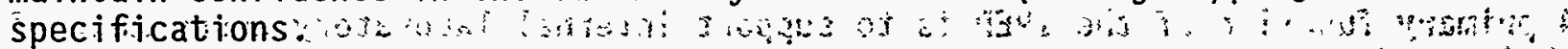

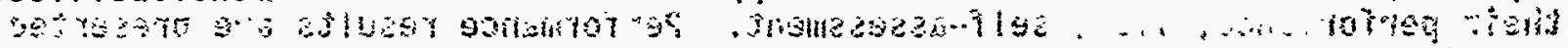

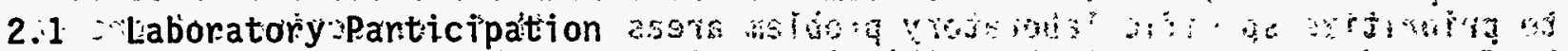

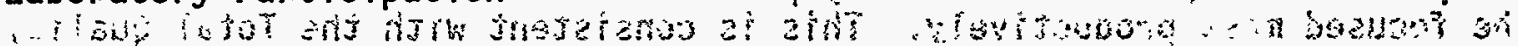

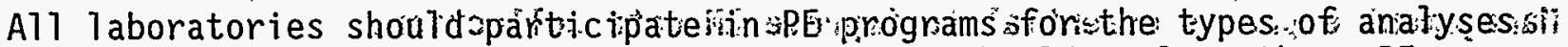
they are providing to EM programs. A laboratory should analyze those PE samples that represent matrix and analyte types being processed in $3 i t s s$ laboratory for EM, not necessarily the full suite of analytes provided in a

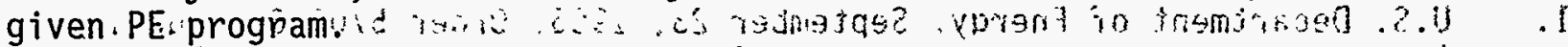

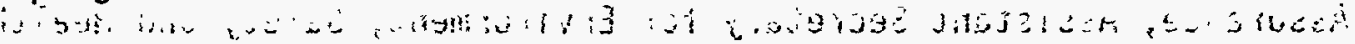

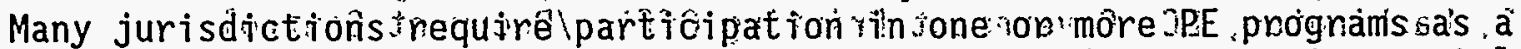
condition for recognition of the laboratory for conducting environmental

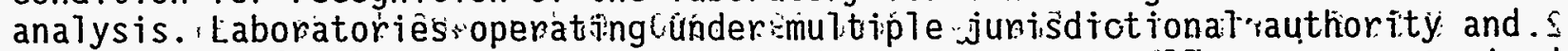

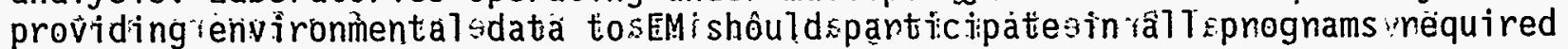

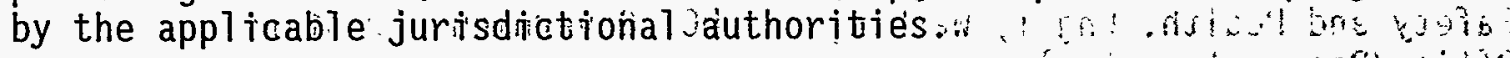

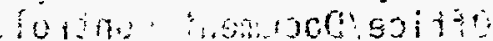

Since regulatory requirements for laboratory qualification and/or

certification a aretconstantl yochanging; the responsibility for determining is

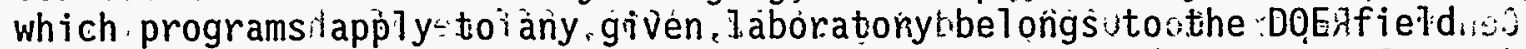
operations officials, „DOErienvinonmental inestioràtion and waste mänágement personnel, Management and Operation (M\&0) directors; and analyticaliofaboratory directors. PE program participation and performance will be monitored and

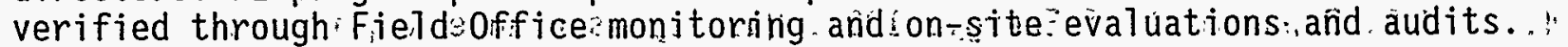

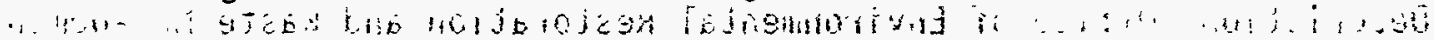

Unless a laboratory is required to participate on a more frequent basis in a particu 7 ar'program because of':EPA/DOE/state: agreement or some other reason, .:

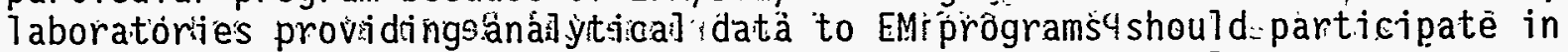
appropriate areas of the PE progiamsigt $t$ asfrequency of: at least once every six months. Participation in the PE $\operatorname{program}(s)$, or hence IPEP, should continue throughout the duration of a Taboratory's support to EM programs.

\subsubsection{Regulatory Performance Evaluation Programs}

As part of its overall responsibility to achieve environmental protection, DOE EM should operate its environmental restoration and waste management programs 
in full compliance with a variety of existing statutes, agreements, and associated regulations. These statutes include:

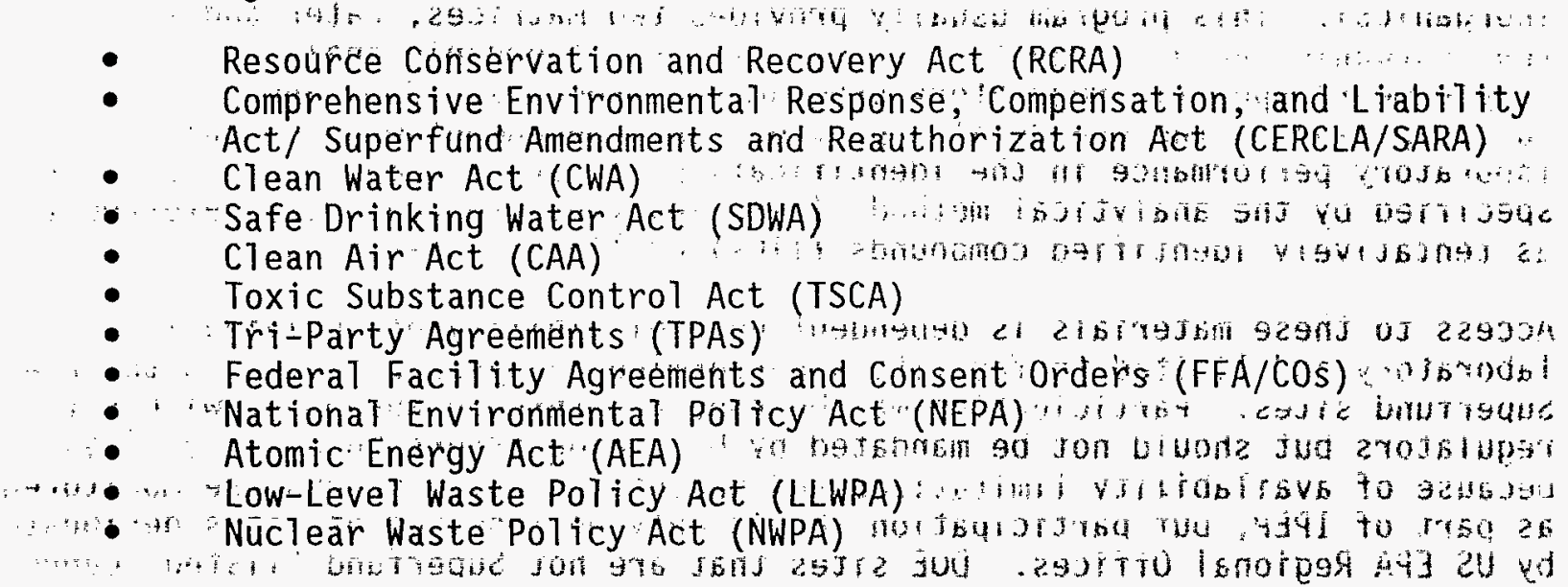

DOE is regulated under each of these statutes and'should carry out why environmental sampling and analys is to show compliance: Various state and federal agencies have authority to enforce these statutes at each.DOE location. It is the responsibility of each EM project manager to use only those Taboratories qualified and/or 7 icensed (if applicable) by prevailing Federál, state, and local regúlatory agencies in the region of the country in where the EM project is located. "The point of ofigin of the samples $i$.e. the location of field site not the location of the analytical laboratory) defines:

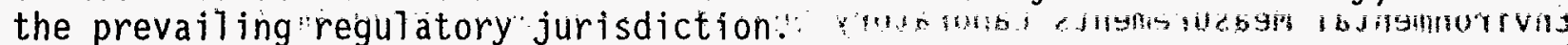

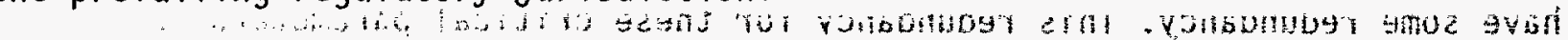
The EPA currentiy operates five major performance evaluation. (PE) programs bity

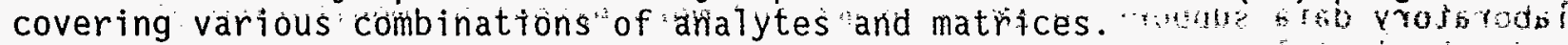
The Office of Water (OW), through the EPA's 'Environmental Monitoring 'Systems: : Laboratory in Cincinnati (EMSL-Ci), operates the Water Supply (WS) and Water Pollution (WP) PE program which test laboratories on a semi-annua fibas is as . part of their Quality Assessment Program supporting the SDWA and CWA. The WS and WP series of PE samples are most often required by state regulatory! si: agencies as part of their laboratory: certification programs. If certain........ analytes (such as oil and grease, cyanide, or ahions) should be montitored for EM programs, then the laboratory should participate in the EMSL-Ci WP PE $A$ ium program. If the laboratory is required to perform drinking water analyses 'for: an EM program, then participation in the EMSL-Ci-WS program is requiredyo ins

The Office of Water, Enforcement and Permits operates the Discharge Monitoring and Reporting Quality Assessment Program as a subset of the WP under the authority of the CWA. This program provides PE samples and formally conducts performance evaluations on thousands of 1 aboratories annual $1 y$. taboratories supplying data for use in the National Pollution Discharge El imination System (NPDES) should participate in this program.: These samples are distributed by: EMSL-C $i$.

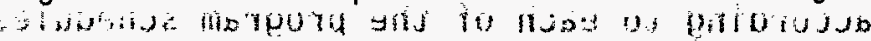

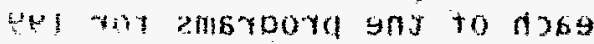

EPA's Contract Laboratory Program Quarterly Blind (CLP QB) are quarterly PE studies for laboratories under contract to the EPA to perform hazardous waste analysis under the CERCLA (Superfund) program. The CLP QB is conducted under the auspices of the Office of Emergençy and Remedial Response (OERR) through the Analytical Operations Branch (AOB) and the Environmental Monitoring " systems Laboratory in Las Vega's (EMSL-LV). In this program the laboratory 
should analyze for all analytes in a given area (i.e; volatile organic compounds, semi-volatile organic compounds, PCBs / pesticides, and / or inorganics). This program usually provides two matrices, water and soil, for the inorganic analyses and a water matrix for the organic analyses. Each sample meets specific regulatory program requirements. Semi-annual participation in the CLP QB also provides an independent way to monitor laboratory performance in the identification of target compounds outside those specified by the analytical method. These analytes are routinely referred to as tentatively identified compounds (TICS) or library search compounds.

Access to these materials is dependent upon eligibility of individual laboratory and limited to facilities performing analyses specific to the EPA's Superfund sites. Participation may be required through agreement with site regulators but should not be mandated by DOE Headquarters to Field Offices because of availability limitations and uncertainties. CLP QBs are monitored as part of IPEP, but participation should only be required at sites designated by US EPA Regional Offices. DOE sites that are not Superfund "listed" cannot require participation from their contractors. If contractors and subcontractors participate in the CLP for other reasons, e.g., EPA contracts, requesting access to their performance results is suggested.

The EPA also conducts the Radiological Intercomparison Study (RIS) program through EMSL-LV. This program is the only regulatory based radiochemistry program and the only current source of PE materials for the assessment of gross radiochemical screening methods. The RIS program and the DOE

Environmental Measurements Laboratory Qual ity Assessment Program (EML QAP) have some redundancy. This redundancy for these critical parameters is programmatically justifiable to assure the regulatory acceptability of laboratory data supporting EM programs and more extensive monitoring of radiochemical laboratory performance.

\subsubsection{DOE EML QAP Performance Evaluation Program}

DOE's EML QAP currently provides PE samples to laboratories for analysis of radionuclides at environmental levels. This program is carried out under the authority of DOE Order 5400.1 governing laboratories providing monitoring/surveillance support to DOE sites, and by EM memorandum governing laboratories providing analytical support to EM. Laboratories providing environmental radiological analyses to EM should participate in EML's Quality Assessment Program. This program provides four matrices: air filters, water, vegetation and soil, semi annually. Tissue samples are provided on an irregular basis.

A summary of the various types of analyses covered by each of the programs discussed in Section 2.1.1 and 2.1.2 is given in Table $1 \mathrm{~A}$ with contact information provided in Table 1B. The frequency of PE sample submission varies according to each of the program schedules. Table 2 provides the schedule for each of the programs for 1993.

In addition to these primary programs, other specialized PE programs are administered by DOE and other Federal groups. The NRC through the DOE Radiological Environmental Sciences Laboratory (RESL) provides radiological PE materials to the nuclear power industry. This program, the Intercomparison Test Program, will be of interest to DOE as it moves into Decontamination and 
Decommissioning (D\&D) projects. The program is run quarterly, usually for gamma emitters. Matrices are determined by the participants on a yearly basis and have included air filters, charcoal filters and water. The program is used to distribute standards and unknowns for the NRC regions. 
TABLE 1A

PRIMARY PERFORMANCE EVALUATION PROGRAMS

\begin{tabular}{|c|c|c|c|c|c|c|c|}
\hline PE Program & Sponsor & Metals & $\begin{array}{l}\text { Volatile } \\
\text { Organics }\end{array}$ & $\begin{array}{c}\text { Semi- } \\
\text { Volatile } \\
\text { Organics } \\
\end{array}$ & $\begin{array}{c}\text { Pesticides/ } \\
\text { PCBS }\end{array}$ & $\begin{array}{c}\text { Radio- } \\
\text { nucl ides }\end{array}$ & $\begin{array}{l}\text { Nutrients/ } \\
\text { Minerals }\end{array}$ \\
\hline $\begin{array}{l}\text { Quality Assessment } \\
\text { Program }\end{array}$ & DOE/EML & & & & & $x$ & \\
\hline MAPEP & DOE/RESL & $x$ & $x$ & $x$ & $x$ & $x$ & \\
\hline EMSL-LV RIS & EPA/EMSL & & & & & $x$ & \\
\hline $\begin{array}{l}\text { Water Supply } \\
\text { Program }\end{array}$ & EPA/OW & $x$ & $x$ & & $x$ & & $x$ \\
\hline $\begin{array}{l}\text { Water Pollution } \\
\text { Study }\end{array}$ & EPA/OW & $x$ & $x$ & $x$ & $x$ & & $x$ \\
\hline CLP Quarterly Blind & EPA/OERR & $x$ & $x$ & $x$ & $x$ & & $x$ \\
\hline
\end{tabular}


TABLE 1B

PERFORMANCE EVALUATION PROGRAM CONTACT LIST

HAZARDOUS

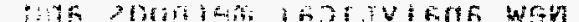

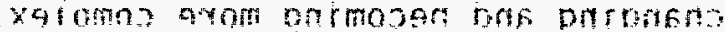

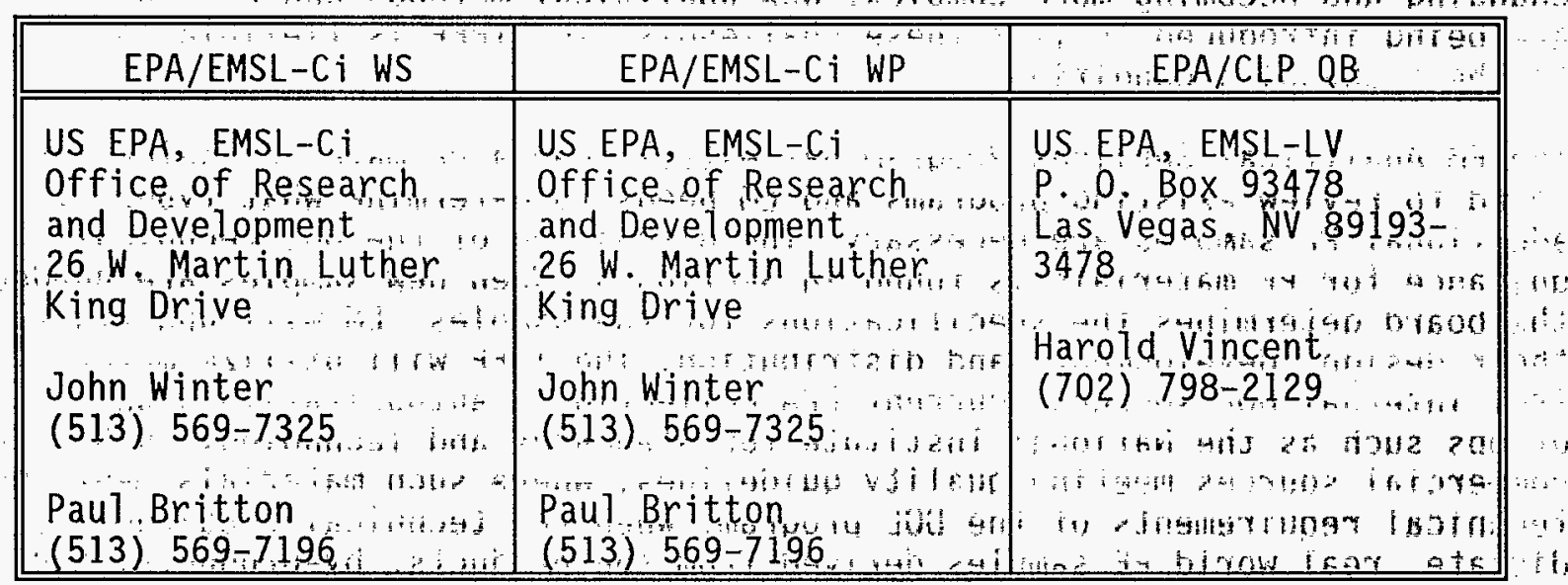

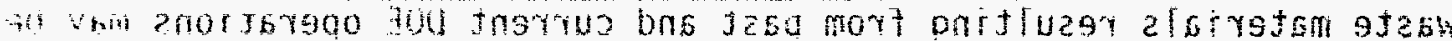

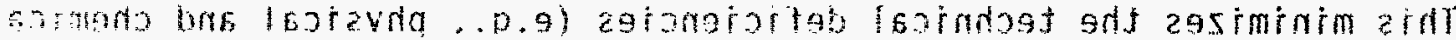

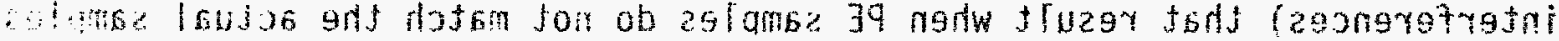

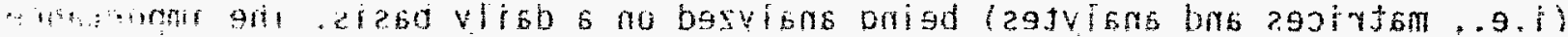

$\therefore$ a

\begin{tabular}{|c|c|c|}
\hline 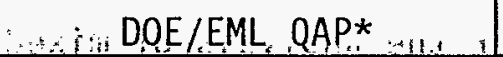 & EPA/EMSL-LV RIS & DOE/RESL MAPEP : \\
\hline 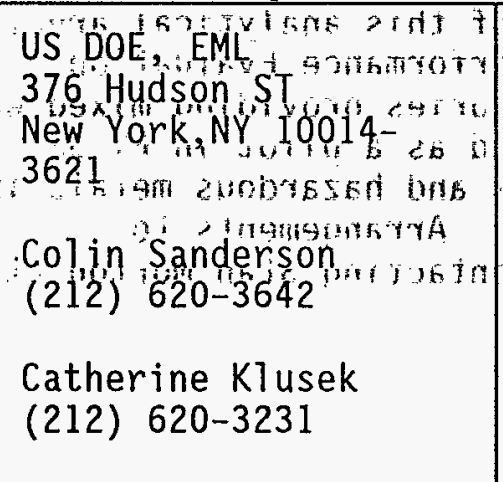 & 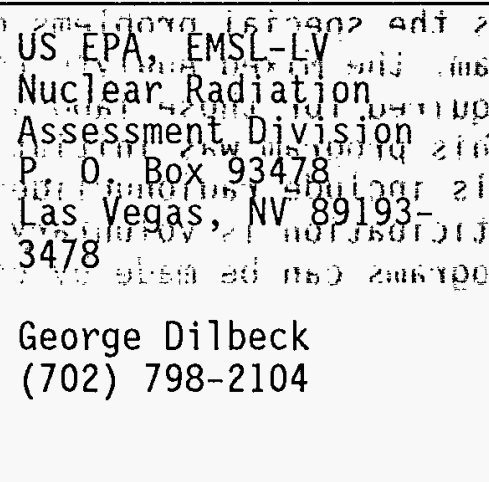 & 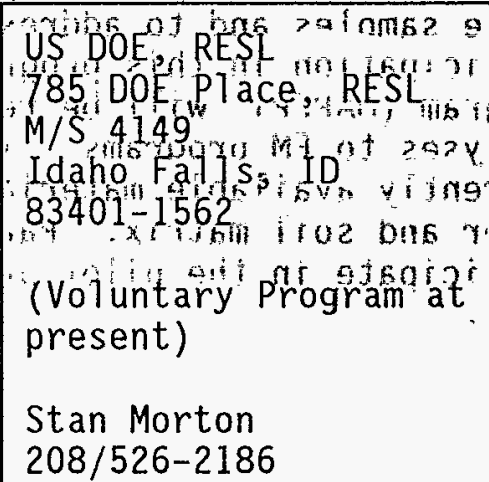 \\
\hline
\end{tabular}




\subsubsection{EM Performance Evaluation Programs}

EM through IPEP has established a PE program focused on its particular data quality requirements. This is necessary to meet EM's responsibility to enhance the technical credibility of its programs and projects. The lists of analytes of interest, sample matrices, and levels of regulatory concern are continually changing and becoming more complex. New analytical methods and new instruments are being introduced to meet these challenges. The IPEP is flexible to respond to these changing conditions.

The EM Analytical Services Program has established a PE material selection board to review existing programs and EM needs to determine what types of additional PE samples are necessary. The discussion of the DOE technical guidance for PE materials is found in Section 3. When new samples are needed, the board determines the specifications for the samples. EM will undertake their design, development, and distribution. The IPEP will utilize materials from internal DOE sources, current EPA collections, authoritative standards groups such as the National Institute for Standards and Technology (NIST), and commercial sources meeting quality guidelines, where such materials meet the technical requirements of the DOE program. When the technical requirements dictate, real world PE samples derived from the products, by-products, and waste materials resulting from past and current DOE operations may be used. This minimizes the technical deficiencies (e.g., physical and chemical interferences) that result when PE samples do not match the actual samples (i.e., matrices and analytes) being analyzed on a daily basis. The importance of analytes of interest, concentration range, and matrix in selecting $\mathrm{PE}$ source materials is discussed in Section 3.

EM-263 is currently developing a PE program to cover the analysis of mixed waste samples and to address the special problems of this analytical area. Participation in this program, the Mixed Analyte Performance Evaluation Program (MAPEP), will be required for those laboratories providing mixed waste analyses to EM programs. This program was initiated as a pilot in FY 93. Currently available materials include radionuclides and hazardous metals in a water and soil matrix. Participation is voluntary. Arrangements to participate in the pilot programs can be made by contacting Stan Morton at RESL. 
TABLE 2

1993 PERFORMANCE EVALUATION DISTRIBUTION SCHEDULE

\begin{tabular}{|c|c|c|c|c|c|}
\hline JANUARY & FEBRUARY & MARCH & APRIL & MAY & JUNE \\
\hline $\begin{array}{l}\text { EPA-CLP } \\
\text { EPA-RIS } \\
\text { Gross A, B } \\
\text { Sr-89, } 90\end{array}$ & $\begin{array}{l}\text { EPA-RIS } \\
1-131 \\
U \text { (Nat) }\end{array}$ & $\begin{array}{l}\text { EPA-WP } \\
\text { DOE-EML QAP } \\
\text { EPA-RIS } \\
\text { Ra-226, } 228 \\
\text { PU-239 }\end{array}$ & $\begin{array}{l}\text { EPA, CLP } \\
\text { EPA-RIS } \\
\text { I-131 } \\
U \text { (Nat) } \\
\text { Mixed A, B, G } \\
\text { EPA-WS }\end{array}$ & $\begin{array}{l}\text { DOE } \\
\text { Mixed Waste }\end{array}$ & $\begin{array}{l}\text { EPA-RIS } \\
\text { Mixed G } \\
\mathrm{H}-3\end{array}$ \\
\hline
\end{tabular}

\begin{tabular}{|c|c|c|c|c|c|}
\hline JULY & AUGUST & SEPTEMBER & OCTOBER & NOVEMBER & DECEMBER \\
\hline $\begin{array}{l}\text { EPA-CLP } \\
\text { EPA-RIS } \\
\text { Gross A, B } \\
\text { Sr-89, } 90\end{array}$ & $\begin{array}{l}\text { EPA-RIS } \\
\text { U (Nat) } \\
\text { Air Filter }\end{array}$ & $\begin{array}{l}\text { EPA-WP } \\
\text { DOE-RIS } \\
\text { Ra-226, } 228 \\
\text { MiTk } \\
\text { DOE-EML } \\
\text { QAP }\end{array}$ & $\begin{array}{l}\text { EPA-CLP } \\
\text { EPA-RIS } \\
\text { I-131 } \\
\text { Mixed A, B, G } \\
\text { EPA, WS }\end{array}$ & $\begin{array}{l}\text { EPA-RIS } \\
\text { Mixed G } \\
\text { H-3 } \\
\text { DOE Mixed } \\
\text { Waste }\end{array}$ & \\
\hline
\end{tabular}




\subsubsection{EM Site-Specific Performance Evaluation Program}

Many EM environmental analytical needs are unique or confined to one or two locations. EM project managers may require site-specific $P E$ samplès to assure that the project data quality requirements are met and maintained over the life of the project. The technical criteria for these materials may be the same as those discussed in Section 3.1. The implementation of these programs is encouraged, but these activities are part of Field office implementation of an integrated evaluation program. EM-263 is currently funding and piloting site-specific development and use of these materials.

\subsection{Numerical Performance Evaluation.}

Each laboratory's numerical PE results are compared with the results of the other individual laboratories and withi the grand average from thellpooled results of all laboratories or the reference value used in any given piogram. The difference between values measures the laboratory's bias: Comparison of the standard deviation provides a measure of the Taboratory precision: Acceptance criteria for both these factors are-estab7ish-based "on/program performance. Site-specific interpretation should be based on specific data requirements.

Individual performance evaluation sample submissions assess performance at the specific time of analysis. Howeverithe primary value of externa participation is to determine and monitor trends ackoss imultiple submissions.

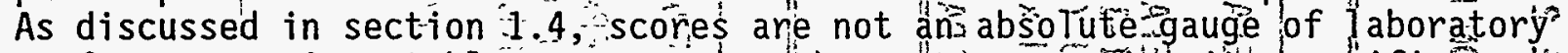
performance. Acceptable-scores can-mask gross errors in site-specific areas of primary concern. Low scores may result from participation in inapproprotate evaluation programs. For example, differences in target analytes: 1 ists. between the sponsoring agency and the laboratory can result in "non-detection" and low evaluation scores that can be readily justified.

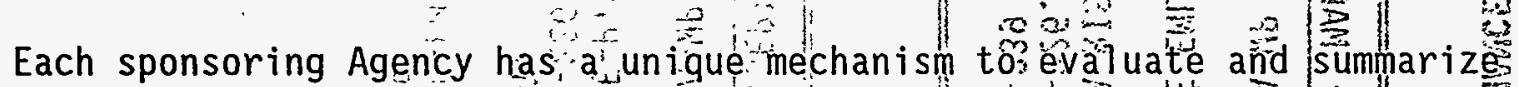
laboratory submissions that meets their programeneds. elt is the lis responsibility of the participating laboratory to identify problems andis develop corrective actions. For example, a cumulative score of < $70 \%$ ồn an EPA program requires formal corrective action. Some states may raise the lower limit of an acceptable score to $90 \%$ for accreditation programs,
Drinking Water.

A primary function of the IPEP to support internal laboratory assessment of their performance, i.e., self-assessment. Performance resulits are presented to prioritize-specific laboratory problem areas so that corrective actions can be focused imost productively. This is consistent with the Total Quality Managements emphasis essential to improve EM:data collection.

The IPEP emphasis on total assessment of data submission, varjabity, as

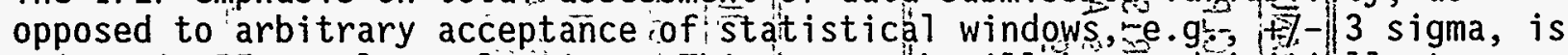
unique in PE sample evaluation. -This approach willobe used initilly to evaluate DOE's internal progŕams; e.g.' EML's QAP, and wi wis expanded to evaluate DOE support laboratory =performance on regulatory programs. However, the ultimate determination of acceptability remains with the sponsoring organization. 
Summary reports of IPEP participation are distributed quarterly to EM $\quad 0.8$ Headquarters and Field Office Management.

\title{
2.3 References
}

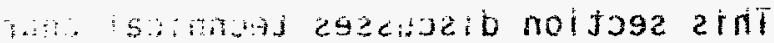

1. Keith, Lawrence H. (editor) 1988 Principles of Environmental Sampling

1. Keith, Lawrence H. (editor). 1988. Principles of Environmental Sampling: American Chemical Society. Chelsea, MI: Lewis Publishers. Taylor, John K. 1988. Quality Assurance of Chemical Measurements, inibit

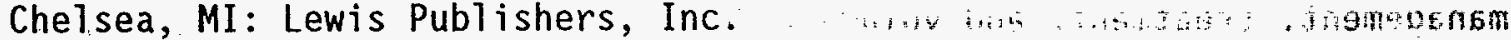

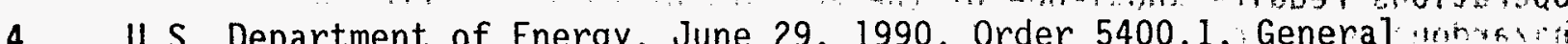
Environmental Protection Program, Assistant Secretary for Environment, : Safety and Health, Chg 1, Washington, DC: Government Printing : Office/Document Control.

U.S. Department of Energy - December 21, General Report No. 0293; and August 12, 1991, Office of the Inspector General Report No. 0295, Washington, DC: Government Printing an 9312

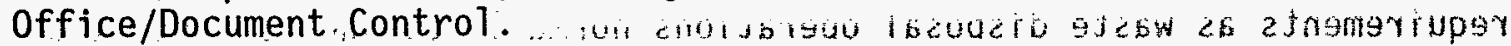

6. U.S Environmental Protection Agency 1990. Contract Laboratory Program Statement of Work for Inorganics Analys is. Document $0 \mathrm{LM}, 01.0 .0$ vraorros

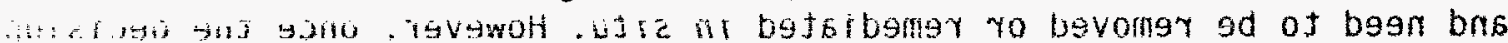

7. U.S... Environmental Protection Agency. 1990. Contract Laboratory Program: Statement of:Work for Organics Analys is. Document ILM 01.8.

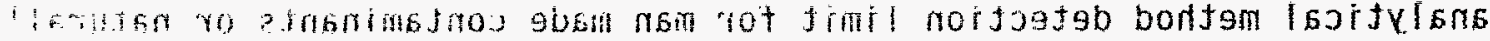

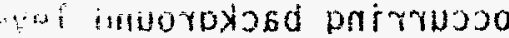

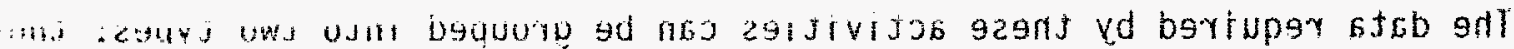

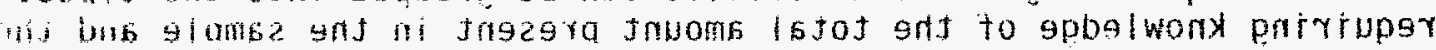

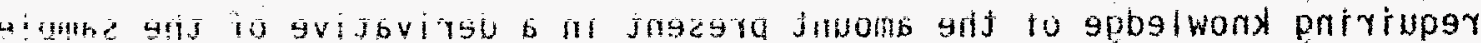

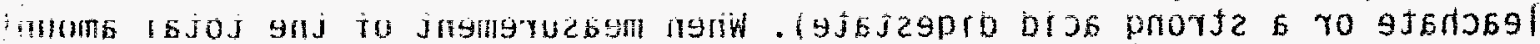

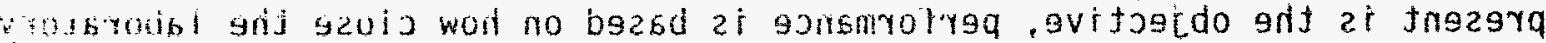

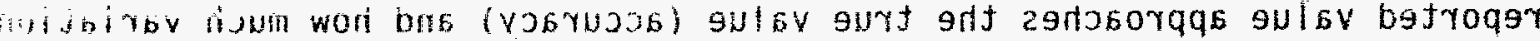

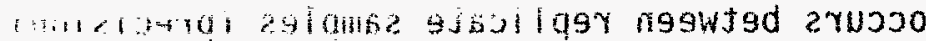

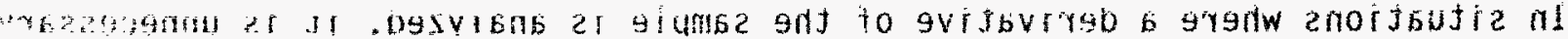

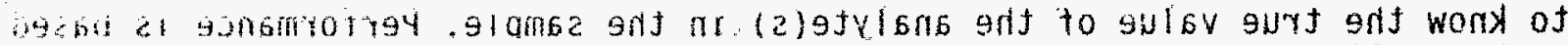
?

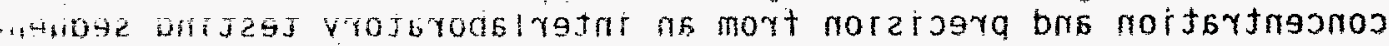

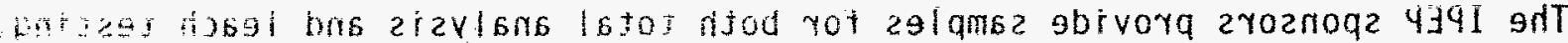

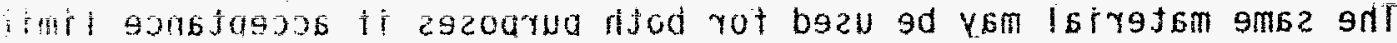

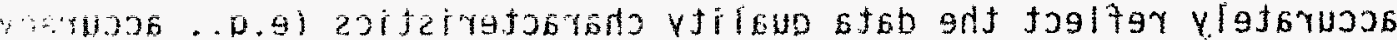
we.

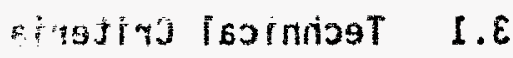

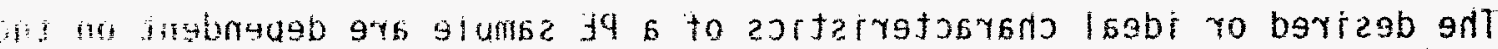

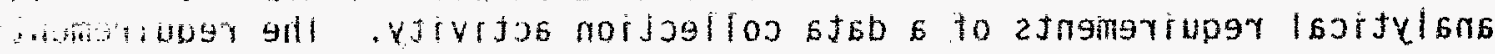




\subsection{TECHNICAL GUIDANCE FOR THE DEVELOPMENT OF PE SAMPLE MATERIALS}

This section discusses technical characteristics for selection of the samples EM needs to meet its requirements and provides an assessment of the samples currently available. It describes the processes and logic employed in the design, development, certification, handling, and storage of PE samples. This section is intended to serve as background for the reader who may be interested in how EM-263 produces its PE samples and for the reader who may have a need to make site specific PE samples.

The IPEP addresses the data quality requirements of on-going operations, waste management, site remediation, and environmental restoration activities. The management, treatment, and volume reduction of wastes produced by on-going DOE operations require knowledge of the amounts of various radionuclides and hazardous organic and inorganic constituents present in the materials. Waste disposal operations under the jurisdiction of RCRA and investigation of derived waste and general waste management required during the CERCLA process require knowledge of the amount of leachable organic and inorganic constituents under the conditions of the EPA's toxicity characteristic leaching procedure (TCLP).

Site characterization and restoration activities have similar data requirements as waste disposal operations normally conducted under the jurisdiction of RCRA. Those materials that fail to meet the toxicity characteristic (as defined by TCLP), or the characteristics of reactivity, corrosivity, and ignitability, or are "Listed Wastes" are considered hazardous and need to be removed or remediated in situ. However, once the decision has been made that the material is hazardous, remediation data requirements usually address the issue of "how clean is clean" and may approach the analytical method detection limit for man made contaminants or naturally occurring background levels.

The data required by these activities can be grouped into two types; those requiring knowledge of the total amount present in the sample and those requiring knowledge of the amount present in a derivative of the sample (a leachate or a strong acid digestate). When measurement of the total amount present is the objective, performance is based on how close the laboratory's reported value approaches the true value (accuracy) and how much variation occurs between replicate samples (precision).

In situations where a derivative of the sample is analyzed, it is unnecessary to know the true value of the analyte(s) in the sample. Performance is based on how well a given laboratory's data approach the average analyte concentration and precision from an interlaboratory testing sequence.

The IPEP sponsors provide samples for both total analysis and leach testing. The same material may be used for both purposes if acceptance limits accurately reflect the data quality characteristics (e.g., accuracy) of the analytical procedures used.

\subsection{Technical Criteria}

The desired or ideal characteristics of a PE sample are dependent on the analytical requirements of a data collection activity. The requirements vary 
from general QA criteria (e.g., the ability to meet contract specifications) to site-specific needs where EM has a narrowly focused objective. The exact degree of PE sample site-specificity is determined partially by the amount of uncertainty the data users (responsible parties and regulators) are willing to accept. As the technical requirements of a sample matrix increase, it is more likely that a site-specific PE sample should be considered. The principle variables that are evaluated in selecting a PE material are discussed below. The development and use of site-specific materials can be cost effective. Based on current pilot projects, their use is expected to grow.

\subsubsection{Analytes of Interest}

The list of analytes of interest (radionuclides, inorganic, and organic) for any PE sample is dictated by the data requirements. Frequently, these requirements come from process knowledge and/or lists published by regulatory groups charged with assuring that ongoing operations do not exceed levels deemed hazardous to the environment. The list of analytes of interest for organic and inorganic hazardous waste constituents can exceed two hundred items. The list of regulated radionuclides is also extensive. This represents a considerable challenge to the producers of multi-analyte PE samples.

The number of analytes of interest, though large, is very small compared to the total number of compounds known to be hazardous to the environment. Prior knowledge of the site frequently indicates that some sub set of the total possible number of these hazardous materials may be present. In this case, the project data requirements should require analysis and reporting of these constituents. They are generally referred to as non-target analytes since they don't appear on regulatory lists. In other cases, there may be no prior knowledge of materials believed present, but there is concern that unlisted compounds may be present at a level sufficient to be deemed hazardous. In such cases, the data user requires that a11 Library Search Compounds (LSCs, a) so referred to as Tentatively Identified Compounds (TICS)) above a certain estimated concentration level be reported. The IPEP will integrate data from a limited number of PE samples addressing this assessment need through the EPA's CLP QB program. Additional monitoring should be provided through site-specific actions.

\subsubsection{Concentration Ranges}

The ability of a laboratory to accurately identify and quantify a specific analyte is directly proportional to its concentration. However, because of limitations in the analytical methods, sample handling problems, and matrix effects, the total analytical process may demonstrate significant non-linear response to analyte concentration. Analytical variability increases as the concentration approaches the detection limit. Therefore, PE samples with a range of analyte concentrations representative of the materials found at EM sites should be utilized by EM project management.

Five relative concentration ranges are of interest to EM because they have serious environmental and financial implications. They usually are defined in terms of regulatory limits or analytical method detection limits, both of which may vary on a site-specific basis and sometimes within a site as well, e.g., dependent upon future 1 and use. The ranges are: 
Above the regulatory limit. Normally, some level well within the concentration range at which laboratories can produce data with a high degree of confidence that normal variations of the data will not affect the decisions made from the data.

- Near the regulatory limit. Normally, some range within which the laboratory can produce data of known quality. At this level, accuracy and precision are important because of the costs associated with either false negatives (unacceptable risk to public or the environment) or false positive (wasted resources).

- Below the requlatory limit. At these levels, accuracy is important because these data frequently determine the extent of long term environmental monitoring. These levels are important if they become the target levels for site clean up or restoration activities.

- At or below the detection limit. This is a very sensitive determination. It is the major source of contention over the present/not present question and the major source of false positive and false negatives in analytical reports. "This is important to the decision process when the decision threshold is at or near the detection limit. As the reported concentration approaches the detection limit, the requirements for relative sensitivity, precision, and accuracy of the measurement process will need to increase to avoid false negatives and false positive. It is variable and depends on the laboratory's execution of the method, the matrix being analyzed, the professional judgement of the staff, and is difficult to evaluate.

- Not detected. If an analyte is not detected it means that the amount of that analyte present, if any, is'less than the detection limit of the analytical method. The Taboratory should report "not detected" and provide the detection limit, or report "less than detection limit". A report of "not present" cannot be substantiated and is not scientifically defen'sible.

\subsubsection{Sample Matrix}

The sample matrix frequently has a significant impact on the reliability of analytical measurements for the total concentration of individual elements or compounds, including radionuclides. In the analys is for organic compounds, the sample matrix is a major variable influencing a laboratory's ability to produce reliable analytical results because the compounds should be separated from the matrix without alteration or loss prior to the actual quantification. In situations where the project requires a high level of confidence in the analytical data, care should be taken in selecting the appropriate matrix for the PE sample. The PE sample matrix should be close to the actual sample matrix to permit accurate evaluation of 1aboratory and method performance for a "representative" matrix.

\subsection{Available Performance Evaluation Samples}

Current sources of certified samples suitable for use in the PE programs are available from NIST, the EPA Cooperative Research and Development Agreement (CRADA) program, and commercial vendors producing samples certified by the 
American Assocjation for Laboratory Accreditation (A2LA) as meeting EPA CRADA standards. Available isamples from existing programs and commercial sources should be used where appropriate matches with routine samples exist. Use of certified materials is preferred over non-certified samples because of their greater technical reliability and credibility within the regulatory community.

\subsection{Production of New Materials}

Currently available materials do not meet ali of EM's needs for PE samples. New samples may be produced by the private' sector or members of the DOE Complex. The level of radiological hazard posed by many of the samples will be a major factor in deciding the best location for production of the materials.

\subsubsection{Identification of: Need}

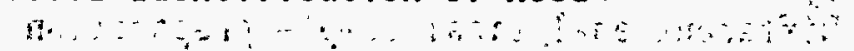

Injdésigning EM PE programs (see Section 2.1.3) a working group made up of members of: EM-263 staff $;$ representatives of specific operating units in the DOE Complex, 'and representatives of the various FSMP prioritize EM's needs and compare them with the list of currently available samples. Where the existing sources are not sufficient to meet the needs, the group establishes detailed specifications for the candjdate PE sample materials. Criteria considered in selecting: materials should include: $:$

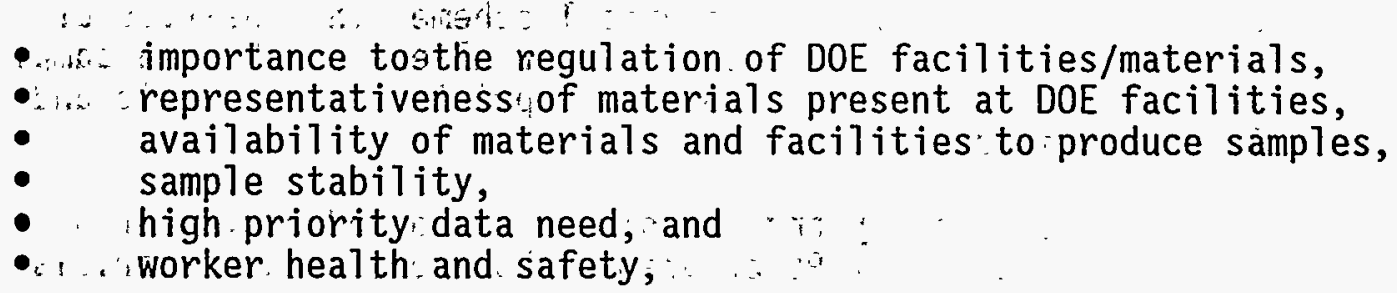

For site-specific PE sample:development; representatives of the Field Office Sample Management organization should establish the total number of replicate samples that need to be produced and establish archive space suitable for storing the samples prior:to distribution. In cases where the samples have a limited shelf, life; the sample:management organizations should coordinate sample production with distribution to the laboratories.

\subsubsection{Sources of Candidate Materials}

There are,three potential, sources of materials for use as PE samples:

$$
\begin{aligned}
& \text { - } \quad \text { ure analytes spiked on to synthetic matrices, } \\
& \text { - } \quad \text { nure analytes spiked on to natural matrices, and } \\
& \text { natural matrices containing the analytes of interest. }
\end{aligned}
$$

Each type of sample is appropriate for certain applications. The relative merits:and shortcomings of the choices are discussed.

Pure compounds spiked on to synthetic matrices: This is the primary mode of production for samples currently used in existing regulatory PE programs. These materials are easy to prepare and can be prepared at specific analyte levels. The component materials are easy to acquire as certified pure from various sources: The proper choice of matrix and spiking procedure minimize sample homogeneity problems during production. and bottling. 
These materials are ideally suited for PE samples of aqueous or liquid matrices. The formulation, bottling, storage, and shipment of concentrates of the analytes of interest in the appropriate 1 iquid matrix is relatively simple and straight forward. Dilution of the concentrate at the laboratory occurs at the time of analysis. This is especially important in the case of organic compounds for which there is a sample holding time requirement. The concentrates are prepared as stable solutions and the holding time clock doesn't start until the sample is diluted to the proper level. Alternatively, full volume water samples have been distributed and used to assess multiple sources of variability external to the laboratory activity (e.g., holding times).

This mode of production is less applicable to solid sample matrices. The analyte/matrix interaction chemistry may differ from the real world sample resulting in sample preparation bias. Different analytical sample preparation techniques are chosen based on the properties of the synthetic matrix/analyte pair rather than on the real world sample. The analysis of samples for organic constituents is generally not amenable to performance testing using these types of samples.

These types of samples are best suited for applications to aqueous solutions and solid materials where aggressive leaching procedures (e.g., strong acid digestion) is a routine part of the analytical scheme. The analytes of interest should be insensitive to destruction or alteration by the sample preparation steps. This approach is most appropriate for inorganic and radiochemical applications.

Because the materials are easily and cheaply produced and distributed, they are widely used for all types of PE programs. However, these materials generally provide very little specific information about laboratory performance on samples of the type found in the DOE Complex.

Pure compounds spiked on to natural matrices. These materials are easy to prepare, requiring only that representative samples of natural matrices be available. Care should be taken that these matrices do not contain concentrations of the analytes of interest, or if they do, this initial concentration is determined and accounted for in preparing the PE material. The analytes can be spiked on the matrix at the desired concentration range. If the matrix is homogenized prior to spiking the analytes, sample homogeneity problems can be reduced to those related to the loading of the analytes on to the matrix. This is not a problem with liquid matrices.

Most of the advantages and drawbacks discussed in the previous section apply to these types of samples as well, but to a lesser extent. Its principle technical advantage over the synthetic matrix is that it can contain the same type of interferences as a natural matrix. However, the natural matrix may contain constituents that react irreversibly with the spiked analytes making it impossible to recover them under the conditions of the analytical method. This type of problem may lead to low analyte recoveries mistakenly attributed to poor laboratory performance.

These types of samples have the same potential applications as samples of analytes spiked to synthetic matrices. For solid matrices, care should be taken that particle size distribution, water content, and total organic 
content are similar between the PE sample and the routine samples being analyzed at the laboratory. These samples can be applied to organic analytes if similarity exists between the matrices.

Natural matrices containing the analytes of interest. These types of samples depend on being able to find representative materials (analytes, concentration, matrix, and interferences) within the EM sphere of operations. They are the most difficult to prepare when there is concern about the loss of volatile constituents. Some loss is inevitable upon processing for sample homogeneity. This loss should be addressed in sample design and production.

These samples have the greatest potential application where a derivative (i.e., a leachate) of the actual field sample is being analyzed. They avoid the problems of non-representative analyte/matrix interactions.

\subsection{Certification of Proficiency Samples}

There are three technical approaches currently being used to certify analyte values in proficiency samples. The best choice of certification protocol for any given PE sample is selected based on the analytical procedures the sample is intended to evaluate. DOE uses the multi-method expert laboratory approach

if it is necessary to know the total concentration of an analyte in a sample. For other types of data requirements either of the multi-laboratory approaches is used.

\subsubsection{Expert Laboratory Certification}

NIST, formerly the National Bureau of Standards (NBS), is recognized as the world leader in producing and marketing high quality reference samples known as Standard Reference Materials (SRMS). The QA principle of "traceability" relates to a laboratory's ability to trace its measurements to NIST certified standards.

The majority of SRMs are certified for selected analytes in terms of total concentration present in the sample. This value is determined by applying multiple analytical techniques including a variety of sample preparation steps, to arrive at the analyte concentration. As a total value, it is free of bias. Multiple analytical techniques is most often applied to inorganic constituents including radionuclides. Multiple analytical techniques has been used for over seventy-five years and is well founded. DOE's EML uses the same approach in their Radiological Quality Assessment Program.

A major limitation of this approach is that the process assumes that the samples will remain stable over time, and therefore the published values are accurate. The approach is also relatively costly and covers a limited range of analytes.

\subsubsection{Multiple Laboratory Certification}

In multiple laboratory certification programs, pre-screened samples of known homogeneity, are submitted to a multi-laboratory testing program. The individual analytical results are collected and statistically treated to produce certified values for the analytes of interest. The A2LA and EPA programs use this technical approach in certifying reference materials. 
Unlike the NIST program, the sample preparation and analytical procedures are usually specified, but by using a large number of laboratories (more than 20 in most cases) systematic and random analytical error are reduced to low values. This protocol does not avoid the bias introduced by the sample preparation and analytical methods. The NIST approach avoids these sources of bias by using multiple methods.

\subsubsection{Performance Based Certification}

In performance based certification, after initial screening to measure the approximate concentration of the analytes of interest, a large batch of material is homogenized and individual samples are prepared for distribution to the participating laboratories. The individual sample results are collected and the average analyte value and uncertainty over the total population of laboratories is determined. This becomes the performance based certified concentration and laboratory performance is measured against this value. The EPA CLP QB uses this approach.

This program differs from the multiple-laboratory certification program in that certification and laboratory assessment occurs simultaneously. It avoids problems of sample stability by having all laboratories analyze the same sample within a narrow time window during which all samples age in a similar manner. If the same samples are used at some future time, only the most recent values are used in evaluating performance.

\subsection{Performance Evaluation Sample Storage}

A11 PE samples should be archived by the EM NSMPs for the useful life of the sample. Samples with an indefinite shelf life (non-radioactive inorganic elements and long lived radionuclides) are kept longer than those with labile analytes (organic compounds and short lived radionuclides).

\subsection{References}

1. Bottre17, D. W., et a1. 1991. Holding Times of Volatile Organics in Water, Waste Testing and Quality Assurance: Third Volume, ASTM STP 1075, D Friedman (editor), Philadelphia, PA: American Society for Testing and Materials.

2. Keith, Lawrence H. (editor). 1988. Principles of Environmental Sampling. American Chemical Society.

3. Maskarinec, M.P., et a1. 1988. Recommended Holding Times of Environmental Samples. Proceedings of U.S. EPA Third Annual Symposium on Solid Waste Testing and Quality Assurance, p. 29-35.

4. Maskarinec, M.P., et a1. November 1992. Stability of volatile Organics in Environmental Soil Samples, Final Report, ORNL/TM-12128, Oak Ridge National Laboratory, Oak Ridge, TN. U.S. Department of Energy Contract No. DE-AC05-840R21400.

5. Taylor, John K. 19887. Quality Control of Chemical Measurements, Chelsea, MI: Lewis Publishers. 
6. U.S. Army. February 1993. Toxic and Hazardous Materials Agency. Practical Reporting Times for Environmental Samples, Oak Ridge National Laboratory, Martin Marietta, 0ak Ridge, TN. DOE IAG No. 1769-A073-Al.

7. U.S. Environmental Protection Agency. May 1983. Preparation of Soi] Sampling Protocol: Techniques and Strategies, EPA/600/4/83/020.

8. U.S. Environmental Protection Agency. 1984. Soil Sampling Quality Assurance User's Guide, 1st Edition, Environmental Monitoring Systems Laboratory, Las Vegas, NV, EPA/600/4/84/043.

9. U.S. Environmental Protection Agency. July 1985. Sediment Sampling Quality Assurance User's Guide, EPA/600/4/85/048.

10. U.S. Environmental Protection Agency. September 1985. Practical Guide for Groundwater Sampling, Environmental Research Laboratory, OK, $\mathrm{EPA} / 600 / 2 / 85 / 104$.

11. U.S. Environmental Protection Agency. 1989. Soil Sampling Quality Assurance User's Guide, 2nd Edition, Environmental Monitoring Systems Laboratory, Las Vegas, NV, EPA 600/8/89/046.

12. U.S. Environmental Protection Agency. May 1990. A Rationale for the Assessment of Errors in the Sampling of Soils, Environmental Monitoring Systems Laboratory, Las Vegas, NV, EPA/600/4/90/013. 


\subsection{LABORATORY CLASSIFICATION AND PERFORMANCE TESTING}

This section describes EM's approach to classifying laboratories, conducting the necessary PE testing, and evaluating their qualifications to perform the required analyses within a classification. Considerable input from the RM group is used to identify and contact candidate laboratories.

\subsection{Classification of Laboratories}

The laboratories are classified according to the types of analysis they are capable of performing. The laboratories should demonstrate that they possess the appropriate ability for the analyses they plan to perform. These standards apply to all laboratories participating in the collection of environmental data for EM activities.

\subsection{Submission of Blind Performance Evaluation Samples}

The FSMPs authorize the submission of a set of PE samples (independently numbered) to the laboratories seeking to support the EM program. Laboratories currently participating in EM recognized PE programs need only to submit their past years results at the time of application for entry into the EM program. Each PE sample set is designed to test certain analytical capabilities of the laboratories. These objectives are established in the initial selection of the PE material and are factors in its design and manufacture. Inherent in that process is the design of how the samples will be submitted to the laboratories. Examples of the factors that are addressed are:

- number of replicate samples,

- choice of independent or inter-laboratory evaluation, and

- simultaneous or sequential submission of replicates.

After the initial qualification of the laboratory, the frequency at which the FSMPs test each individual laboratory should be related to the importance of the work being handled by the laboratory and the results of the review of the data by the DOE data user as well as regulatory requirements (i.e., the sites FFAs). Semi-annual re-testing is the minimum requirement. Sensitive or critical analyses and questionable data should prompt more frequent testing.

The data from single blind PE studies is submitted directly to the NSMP's data evaluation group. For PE studies utilizing unidentifiable samples, submission of the completed PE reports to the laboratories is conducted in such a manner that the laboratories are not alerted to the fact that specific samples are/were PE materials. Individual sample test results are collected and reduced using accepted statistical approaches. This data constitutes the numerical data used to evaluate laboratory performance.

\subsection{Performance Evaluation Sample Data Base}

A comprehensive data base containing both narrative and numerical data related to the selection, initial screening, homogenization (and testing), certification testing, and laboratory performance testing of each PE sample should be maintained. Results of both internal and external corrective actions and any re-testing by the laboratories should be collected and compiled. EM project management is responsible for the data base operation and the 
technical validity and credibility of the PE data. These responsibilities include:

- development and implementation of the technical approaches that should be used in establishing sample homogeneity, certified values, sample stability, and individual 1aboratory performance.

- collecting, reducing, maintaining, and distributing all data related to the PE program.

- determining the technical soundness of the existing PE programs and relating these programs to the EM project DQOS. 


\section{APPENDIX I}

\section{LIST OF ACRONYMS}

\begin{tabular}{|c|c|c|}
\hline $\begin{array}{l}\text { A2LA } \\
\text { AEA } \\
\text { AOB } \\
\text { AS } \\
\text { ASD } \\
\text { ASP }\end{array}$ & $\begin{array}{l}- \\
- \\
- \\
-\end{array}$ & $\begin{array}{l}\text { American Association for Laboratory Accreditation } \\
\text { Atomic Energy Act } \\
\text { Analytical Operations Branch } \\
\text { Analytical Support } \\
\text { Analytical Services Division } \\
\text { Analytical Services Program }\end{array}$ \\
\hline $\begin{array}{l}\text { CAA } \\
\text { CERCLA }\end{array}$ & - & $\begin{array}{l}\text { Clean Air Act } \\
\text { Comprehensive Environmental Resource,Compensation and } \\
\text { Liability Act }\end{array}$ \\
\hline $\begin{array}{l}\text { CLP } \\
\text { CLP-QB } \\
\text { CRADA } \\
\text { CWA }\end{array}$ & $\begin{array}{l}- \\
- \\
-\end{array}$ & $\begin{array}{l}\text { Contract Laboratory Program } \\
\text { Contract Laboratory Program, Quarterly Blind } \\
\text { Cooperative Research and Development Agreement } \\
\text { Clean Water Act }\end{array}$ \\
\hline $\begin{array}{l}\text { D\&D } \\
\text { DOD } \\
\text { DOE } \\
\text { DOT } \\
\text { DQO }\end{array}$ & $\begin{array}{l}- \\
- \\
- \\
-\end{array}$ & $\begin{array}{l}\text { Decontamination and Decommissioning } \\
\text { U.S. Department of Defense } \\
\text { U.S. Department of Energy } \\
\text { U.S. Department of Transportation } \\
\text { Data Quality Objectives }\end{array}$ \\
\hline $\begin{array}{l}\text { EM } \\
\text { EM-263 } \\
\text { EML } \\
\text { EML-QAP } \\
\text { EMSL } \\
\text { EMSL-Ci }\end{array}$ & $\begin{array}{l}- \\
- \\
- \\
-\end{array}$ & $\begin{array}{l}\text { Environmental Restoration and Waste Management } \\
\text { Analytical Services Division of EM } \\
\text { Environmental Measurements Laboratory } \\
\text { EML Quality Assessment Program } \\
\text { Environmental Monitoring System Laboratory } \\
\text { Environmental Monitoring Systems Laboratory, } \\
\text { Cincinnati }\end{array}$ \\
\hline $\begin{array}{l}\text { EMSL-LV } \\
\text { EPA } \\
\text { ESA }\end{array}$ & $\begin{array}{l}- \\
-\end{array}$ & $\begin{array}{l}\text { Environmental Monitoring Systems Laboratory, Las Vegas } \\
\text { U.S. Environmental Protection Agency } \\
\text { Environmental Sampling and Analys is }\end{array}$ \\
\hline $\begin{array}{l}\text { FFA/CO } \\
\text { FSMP }\end{array}$ & - & $\begin{array}{l}\text { Federal Facility Agreement and Consent Orders } \\
\text { Field Sample Management Program }\end{array}$ \\
\hline $\begin{array}{l}\text { IG } \\
\text { IPEP }\end{array}$ & - & $\begin{array}{l}\text { Office of the Inspector General } \\
\text { Integrated Performance Evaluation Program }\end{array}$ \\
\hline LLWPA & - & Low-Level Waste Policy Act \\
\hline $\begin{array}{l}\text { M\&O } \\
\text { MAPEP }\end{array}$ & - & $\begin{array}{l}\text { Management \& Operation } \\
\text { Mixed Analyte Performance Evaluation Program }\end{array}$ \\
\hline
\end{tabular}




$\begin{array}{lll}\text { NBS } & - & \text { National Bureau of Standard } \\ \text { NEPA } & - & \text { National Environmental Policy Act } \\ \text { NIST } & - & \text { National Institute of Standard (Formerly NBS) } \\ \text { NRC } & - & \text { Nuclear Regulatory Commission } \\ \text { NSMP } & - & \text { National Sample Management Program } \\ \text { NWPA } & - & \text { Nuclear Waste Policy Act } \\ \text { OERR } & - & \text { Office of Emergency and Remedial Response } \\ \text { OTD } & - & \text { Office of Technology Development } \\ \text { OW } & - & \text { Office of Water } \\ \text { PCB } & - & \text { Polychlorinated Biphenyl } \\ \text { PE } & - & \text { Performance Evaluation } \\ \text { QA } & - & \text { Quality Assurance } \\ \text { QA/QC } & - & \text { Quality Assurance/Quality Control } \\ \text { QAP } & - & \text { Quality Assurance Program } \\ \text { QB } & - & \text { Quarterly Blind } \\ \text { QC } & - & \text { Quality Control } \\ \text { RCRA } & - & \text { Resource Conservation and Recovery Act } \\ \text { RESL } & - & \text { Radiological and Environmental Sciences Laboratory } \\ \text { RIS } & - & \text { Radiological Intercomparison Study } \\ \text { RM } & - & \text { Resource Management } \\ \text { SARA } & - & \text { Superfund Amendment and Reauthorization Act } \\ \text { SDWA } & - & \text { Safe Drinking Water Act } \\ \text { SEN } & - & \text { Secretary of Energy Notice } \\ \text { SRM } & - & \text { Standard Reference Material } \\ \text { TCLP } & - & \text { Toxicity Characteristic Leaching Procedure } \\ \text { TIC } & - & \text { Tentatively Identified Compound } \\ \text { TPA } & - & \text { Tri-Party Agreement } \\ \text { TQM } & - & \text { Total Quality Management } \\ \text { TSCA } & - & \text { Toxic Substance Control Act } \\ \text { WP } & - & \text { Water Pollution } \\ \text { WS } & - & \text { Water Supply }\end{array}$

